\section{Implementing the protocol of a pilot randomized controlled trial for the recovery-oriented intervention to people with psychoses in two Latin American cities}

\author{
Implementação de um protocolo para um estudo \\ piloto randomizado e controlado sobre uma \\ intervenção voltada para a recuperação \\ em pessoas com psicoses em duas \\ cidades latino-americanas
}

\section{Implementando un protocolo para una prueba piloto controlada aleatorizada en una intervención orientada a la recuperación de personas con psicosis en dos ciudades latinoamericanas}

QUESTÕES METODOLÓGICAS

METHODOLOGICAL ISSUES

Franco Mascayano 1,2

Ruben Alvarado 3

Howard F. Andrews 1

Maria Jose Jorquera 4

Giovanni Marcos Lovisi 5

Flavia Mitkiewicz de

Souza 6

Charissa Pratt 1

Graciela Rojas ${ }^{4}$

Maria E. Restrepo-Toro ${ }^{7}$

Kim Fader 1

Prakash Gorroochurn 1

Sandro Galea 8

Catarina Magalhães

Dahl 6
Jacqueline Cintra 5

Sarah Conover 9

Maria Soledad Burrone 3

Joy Noel Baumgartner 10

Robert Rosenheck 7

Sara Schilling 3,4

Keli Rodrigues Sarução 5

Peter Stastny 11

Eric Tapia 3

Maria Tavares

Cavalcanti 6

Eliecer Valencia 3

Lawrence H. Yang 1,12

Ezra Susser 1,2

doi: 10.1590/0102-311X00108018

Correspondence

F. Mascayano

Department of Epidemiology, Mailman School of Public Health, Columbia University.

722 West 168th St., Room 1030, New York / NY - 10032, U.S.A.

fm2582@cumc.columbia.edu

1 Mailman School of Public Health, Columbia University, New York. U.S.A.

2 New York State Psychiatric Institute, New York, U.S.A.

3 Instituto de Ciencias de la Salud, Universidad de O'Higgins, Rancagua, Chile.

4 Facultad de Medicina, Universidad de Chile, Santiago, Chile. 5 Instituto de Estudos em Saúde Coletiva, Universidade Federal do Rio de Janeiro, Rio de Janeiro, Brasil.

6 Instituto de Psiquiatria, Universidade Federal do Rio de Janeiro, Rio de Janeiro, Brasil.

7 Yale School of Medicine, Yale University, New Haven, U.S.A. 8 School of Public Health, Boston University, Boston, U.S.A.

9 Silberman School of Social Work, Hunter College, New York, U.S.A.

10 Global Health Institute, Duke University, Durham, U.S.A.

${ }^{11}$ Community Access, Inc., New York, U.S.A.

12 College of Global Public Health, New York University, New York, U.S.A. foundation for planning a large-scale multi-site RCT to establish the efficacy of recovery-oriented interventions such as CTI-TS in Latin America.

Community Mental Health Services; Psychotic Disorders; Randomized

Controlled Trial; Global Health 


\section{Background}

\section{Community care for people with psychoses in Latin America}

In 1990, the Caracas Declaration marked the beginning of a new era in mental health care in Latin America 1. This Declaration put forth a multifaceted progressive agenda, within which one of the key goals was to shift the major locus of care for people with psychoses and other severe mental disorders from psychiatric hospitals to community settings. Several Latin American countries have developed broad societal legislation and made remarkable strides towards offering care in the community. This progress, however, has been uneven across countries 2,3.

Community Mental Health Centers (CMHCs) are now the primary locale for outpatient treatment of individuals with psychoses in most Latin American countries 3. We describe here a pilot randomized clinical trial (RCT) (Registration number: NCT01995864) of a recovery-oriented, task-shifting intervention for individuals with psychosis, which was conducted at CMHCs in two Latin American cities: Rio de Janeiro (Brazil) and Santiago (Chile). The goal of this paper is two-fold: (i) to describe the study protocol of the pilot RCT, and (ii) to discuss some challenges and lessons learned when implementing it. Although unorthodox in its format, this piece can be of value for those who plan to design and conduct a pragmatic trial of this novel kind of intervention in Latin America and elsewhere, in low- and middle-income countries (LMICs). By describing what we planned to do and what was finally implemented, we hope to shed some light on the difficulties such endeavors often face.

Both Brazil and Chile are among the most advanced Latin American countries regarding mental health care ${ }^{3}$. Chile, for instance, currently has a minimal number of beds in asylums ${ }^{4}$ and Brazil is moving towards that goal ${ }^{5}$. In addition, both countries have a growing number of CMHCs and have paid some attention to the links between CMHCs and primary health care. We note, however, that many other countries have also made substantial and growing investment to facilitate transition from hospital to community care 6 . The intervention tested in this pilot RCT was designed to be delivered at CMHCs and to be adaptable for those countries.

Generally, CMHCs in Chile and Brazil provide basic, crucial clinical services, including medications and psychosocial interventions. Nonetheless, there are still fewer CMHCs than needed. Partly as a result of their large coverage areas, the services offered tend to have significant limitations, four of which are especially relevant to the design of this RCT. First, they tend to have minimal resources for the provision of in vivo community services, that is, services provided outside the clinic, in the patient's home or other community settings 7 . Second, they face several challenges in providing coordinated care between different types of services (i.e., primary care, other specialized mental health services, emergency services etc.) 8 . Third, they rarely engage (and almost never employ) the patients themselves (i.e., peer workers) in planning or providing mental health care 9 . Fourth, despite the fact that recovery-oriented approaches have been increasingly adopted in many high-income countries (HICs) 10, such services are rarely offered in Latin America and they are in no way part of universal health care services. In this context, a recovery-oriented approach focuses on expanding the ability of people to rebuild a positive sense of self and social identity, despite the challenge of continuing to deal with mental health problems or related disabilities 11 .

A series of studies has rigorously documented some of these limitations in Chile and Brazil 12,13,14. In Chile, nationwide studies of psychosocial interventions offered by CMHCs to patients with psychoses found that only a minority $(<25 \%)$ were receiving any systematic evaluation or plan for psychosocial intervention 12. Similar findings were reported in Brazil, by a systematic review including 35 studies on the assessment mental health services 13 . Most reports highlighted the lack of training among professionals at CMHCs to provide outreach interventions and coordinate mental health care with primary care and other services 14 .

Nevertheless, there is progress. The pace might well be accelerated by leveraging the Mental Health Action Plan of the World Health Organization (WHO) 15, in conjunction with the 2016 Lima Declaration on mental health reform in the Latin American context 2. For example, Chile and Brazil have legislated the provision of disability payments and free clinic services for individuals with mental illness, and have legally mandated that mental health services should promote social integration 16,17 . At the same time, a small but rapidly growing advocacy movement of patients and 
their families is applying pressure for these mandates to be enforced 6 . The intervention tested here, as described below, was built upon this advantageous platform.

\section{Critical Time Intervention-Task Shifting (CTI-TS) to strengthen community care and promote recovery}

This pilot RCT of Critical Time Intervention-Task Shifting (CTI-TS) was conceived as a crucial step geared towards a broader objective of encouraging regional efforts to address the aforementioned limitations in community care. One of the reasons for conducting the trial in two urban areas was to verify that CTI-TS is applicable to the marginalized, poor urban communities where many people in Latin America reside.

The RCT was conducted under the auspices of RedeAmericas, a regional network for mental health research in the Americas (NIMH U19MH095718). RedeAmericas is one of five such "collaborative hubs" funded by the United States National Institute of Mental Health (NIMH) in Latin America, Africa, and South Asia. A key feature of all hubs was the inclusion of a task-shifting component, in which non-professionals would be involved in the delivery of mental health services.

CTI-TS has roots in the evidence-based Critical Time Intervention (CTI) used in HICs 18 . CTI is a well-known, time-limited psychosocial model designed to mobilize support for vulnerable populations during critical periods. Originally developed and tested with individuals during the transition from homeless shelters to community housing, CTI has since been applied during many other critical periods as, for example, the months following discharge from inpatient psychiatric treatment, the time when a person is first offered services at a mental health clinic, or when a person first seeks to reconnect with a mental health clinic after a long lapse. The CTI model has been used with different marginalized communities such as veterans, people with mental illness, people who have been homeless or in prison, people who have suffered serious trauma, among other groups. Numerous studies, including randomized controlled trials, have demonstrated the effectiveness of this model 18,19,20 (see a full list of publications here: https://www.criticaltime.org/). A noteworthy finding is that the positive impact of this time-limited intervention can yield sustained benefits.

The CTI-TS formulation was built on a series of previous studies by our colleagues from the Federal Universiy of Rio de Janeiro (UFRJ/Brazil) 21,22,23. Pilot studies included the marginal communities of Rio de Janeiro, where basic infrastructure, such as transportation, is often inadequate; formal jobs are scarce; and violence is endemic 24. Many other urban areas in Latin America include similarly marginal communities. A major challenge in developing the final version of CTI-TS was to ensure that it would be applicable to these marginal communities, as well as to the majority of the population.

In its broadest terms, CTI-TS seeks to improve the lives of people with psychoses residing in the community and receiving mental health care at CMHCs, a care which is delivered by lay community mental health workers (CMHWs) and peer support workers (PSWs) based in CMHCs and supervised by mental health professionals. In this trial, both the CMHWs and PSWs were paid employees; they worked in pairs, in a synergistic manner, using their distinct capabilities and expertise. The CTI-TS addresses the four limitations of existing CMHC care noted earlier by: (i) providing in vivo community services; (ii) enhancing ties between care provided by primary care centers for general health conditions and secondary mental health center care for mental disorders; (iii) using paid peer support workers to deliver mental health care; and (iv) offering recovery-oriented services. Finally, CTI-TS is designed to be a readily adaptable, short-term intervention with a lasting impact, having the potential to improve community care across a wide swath of the region. In a context of limited resources, a 9-month intervention can be scaled up to reach virtually all individuals with psychotic disorders.

The CTI-TS does not replace usual care but rather complements it. As CTI-TS is a 9-month intervention with a hypothesized lasting impact at 18 months, its efficacy depends upon sustained improvement. We hypothesized that participants of this pilot RCT who received CTI-TS rather than usual care alone would show a trend toward improved health-related quality of life and report fewer unmet needs 18 months after the initiation of the 9-month CTI-TS intervention. We also planned to examine secondary outcomes, such as recovery orientation, disability, continuity of care, and substance use. 


\section{Methods/design}

\section{Trial design}

This pilot RCT was conducted from 2014 to 2017 . While the primary data collection for the trial is over, we are still gathering supplementary information from medical records and qualitative interviews about its implementation. We believe this will enhance our interpretation and understanding of the findings, and plan to use such data for the main reports.

Trial participants were randomized to one of the two groups, either usual care plus the CTI-TS intervention (intervention group) or usual care alone (control group), in a 1:1 ratio and stratified by city (Rio de Janeiro: $\mathrm{N}=50$; Santiago: $\mathrm{N}=60$ ).

\section{Settings}

In both cities, the trial was conducted in specified CMHCs and their coverage areas. Participants in Santiago were recruited from five CMHCs, which served a population of 1,245,000 inhabitants, corresponding to about $18 \%$ of Santiago's population $(7,037,000$ million) (Regional Ministry of Health Secretariat of the Metropolitan Region. http://www.asrm.cl/archivoContenidos/poblacion-total -rm-2013.pdf, accessed on 17/Aug/2017). In these areas of coverage, the percentage of people living below the poverty line ranged between $21 \%$ and $42 \%$ (the average estimated for Chile is 20.9) (Chilean Ministry of Social Development. http://observatorio.ministeriodesarrollosocial.gob.cl/casen-multidimensional/casen/casen_2015.php, accessed on 17/Aug/2017). In Rio de Janeiro, participants were recruited from three CMHCs, which were the primary adult mental health services for areas with approximately 2,400,000 residents, representing about 37\% of Rio de Janeiro's total population (Brazilian Ministry of Health. http://www.ans.gov.br/anstabnet/\#, accessed on 17/Aug/2017). The city is characterized by major social and economic contrasts, with some neighborhoods presenting high rates of robbery, violence and poverty 25 .

\section{Study participants and recruitment}

Originally, we sought to recruit people with psychotic disorders and their primary caregivers. We were unable, however, to recruit caregivers due to a series of obstacles in each city, such as limited human resources, administrative complications, and contextual barriers such as limited transportation.

\section{- Eligibility criteria for trial participants}

The eligibility criteria for trial participants were:

(1) 21-65 years old;

(2) Any psychotic disorder based on the International Classification of Diseases - 10 th revision (ICD-10) criteria, including both non-affective (e.g., schizophrenia) and affective psychosis (e.g., bipolar disorder);

(3) No longer than 3 months since the first visit to the CMHC;

(4) Not expressing active suicidal ideation;

(5) Not presenting cognitive or other sensorial impairmentthat is likely to preclude reliable assessment via interview procedures.

\section{Recruitment and screening}

There were 110 trial participants recruited, as seen in Figure 1, who were enrolled at five CMHCs in Santiago and at three CMHCs in Rio de Janeiro.

Each CMHC designated a staff member to identify potential trial participants. When a potential trial participant was identified, the professional filled out a referral form and proceeded to conduct a screening interview to confirm eligibility or exclusion. For those individuals who met the inclusion 


\section{Figure 1}

Flowchart of recruitment and allocation.

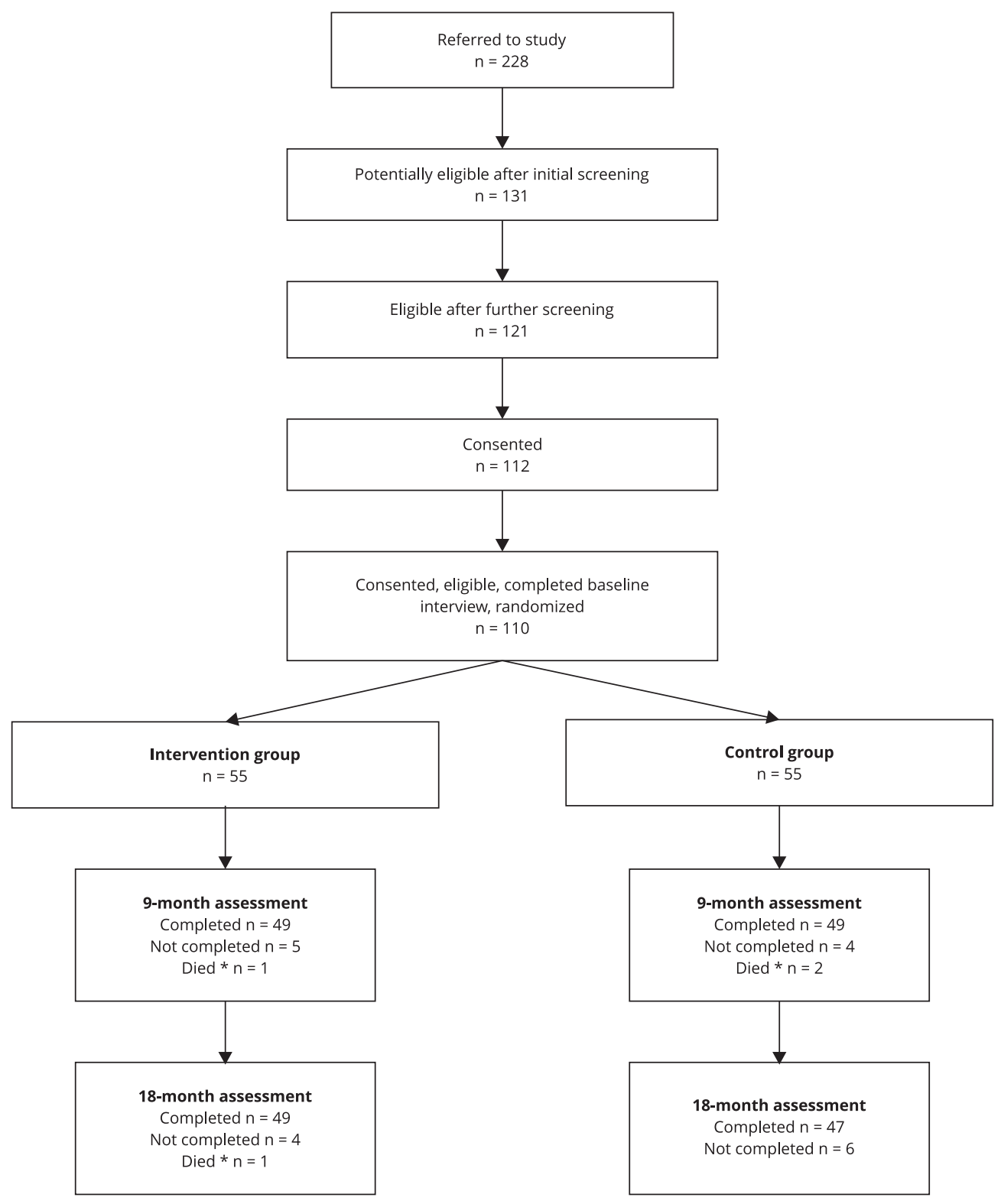

* Causes of death: lung infection, pulmonary embolism, brain tumors, cardiac event.

criteria, a CMHC health professional evaluated capacity for consent through an adapted form based on the MacArthur Competence Assessment Tool for Clinical Research 26. This professional was usually a psychiatrist or psychologist. After the capacity for consent was verified, a first contact was scheduled between the potential trial participant and a research interviewer. Research interviewers had also undergone specific training on the protection of human research subjects. In this meeting, the research interviewer verified eligibility and then informed the potential trial participant about the nature of the study, also describing the randomized assignment to intervention or control group, 
potential risks and benefits, and the evaluation process, which included assessments at baseline, 9-months and 18-months follow-up. The importance of interviewers remaining "blind" to group assignment was explicitly discussed, and participants were asked not to report information that could indicate to which group they were assigned. An unblinded person called "registration designee" was in charge of ensuring that the research team (including interviewers) remained blind in each city. His/her tasks included (a) handling the "randomization log", which served as the on-site link between the study ID, the randomization assignment, and the information needed to identify the participant, such as name, sex, and age; (b) notifying the intervention team once a participant was randomized to CTI-TS; (c) communicating the study ID and name of an incoming participant to the research interviewer; (d) examining and reporting any adverse events if that occurred during the trial; and (e) reporting any drop outs from the study. This person was trained on NIH guidelines to assure data quality management in clinical research. He/she only used ID/s when talking and communicating with principal investigators and research team, to maintain study blinding. Only she/he had access to the randomization log, which was an encrypted sheet stored in a protected computer in each city.

\section{Randomization and treatment allocation}

\section{- Sequence generation and allocation concealment}

Randomization took place after the baseline interview was completed and eligibility had again been confirmed, using the web-based randomization assignment program provided by the Data Coordinating Center of Columbia University (CU DCC/United States). Patients were randomized separately within the study cities to reduce imbalance between groups (i.e., block randomization). A four-digit study code (henceforth referred to as the study ID) was assigned to each consenting trial participant as the basis for collecting de-identified data. The registration designee in each city was assigned to enter information in a digital randomization log after sample distribution. When a new participant was randomized to CTI-TS, the local intervention team received a notification containing the trial participant's name. The intervention team retrieved contact details from the referral professional and kept a confidential list of trial participants assigned to CTI-TS.

\section{Interventions}

\section{Intervention arm}

\section{- Personnel: selection and recruitment}

The intervention was delivered by pairs comprising a PSW and a CMHW. The approach to selecting and recruiting the paid-PSWs was specially tailored given the novelty of the intervention and aimed at: (a) identifying potential peers at CMHCs and following a series of steps to select those most suitable for the role of peer support worker, and (b) training those selected before their guidance together with CMHWs, to provide them with some advantage and increase personal confidence prior to interactions with CMHWs and mental health professionals.

While the criteria were the same, the process by which PSWs and CMHWs were recruited and trained in the two sites varied slightly due to differences in the sociocultural contexts and service systems of the two cities. For instance, the Santiago team opted for recruiting PSWs from the CMHCs where the RCT was carried out. Some advantages of this approach were that PSWs were very familiar with the CMHCs culture and operations, had relationships with CMHC professionals, and resided in the communities served by the CMHCs, where the RCT participants also lived. In Rio de Janeiro, on the other hand, the team decided to recruit potential PSWs from CMHCs that were not included in the trial, and query patients' organizations or groups (e.g., "User's Voice" and "Transversões") to propose individuals who might have the potential to become peers for CTI-TS. One advantage of the latter approach was that members of these groups were already familiar with recovery-oriented principles and ways in which patients could assist one another. Regarding the recruitment of CMHWs, the 
Santiago team enlisted individuals who had no prior formal training in conducting health or mental health interventions. They selected CMHWs based on their experience with and passion for working with vulnerable populations, their familiarity with the areas surrounding the CMHCs and their community services. In Rio de Janeiro, however, CMHWs were recruited from a pool of graduates from a training course, at the Joaquim Venâncio Polytechnic School/Oswaldo Cruz Foundation, for community health workers with previous experience working with people with severe mental illness.

\section{- Personnel: training and supervision}

The CMHWs and PSWs were trained on CTI-TS by a first phase of didactic training and a second phase of on-the-job training, which took around 9 months. In both phases, the training was guided by a CTI-TS Training Manual (that was developed by two authors: S.C., M.E.R.-T.), pilot tested, and then refined throughout one year. The development of such manual posed a series of challenges. For instance, the manual had to be translated from English to Portuguese and Spanish, and vice versa. In other words, we had to standardize concepts across three different languages. Some of those concepts were particularly difficult to translate such as "recovery orientation", given that the words "recuperacion" or "recuperação" had a different meaning in Spanish and Portuguese (e.g., reduction or absence of symptoms). Another challenge was related to specifying and distinguishing the core components of CTI-TS from those that should be adaptable to each setting. Such action required several discussions with local stakeholders, including with CMHWs and PSWs themselves. Our goal was to keep the ingredients that make CTI-TS an effective approach (e.g., shared decision-making) but, at the same time, to add contextual-dependent modifications (e.g., meeting with clients at CMHCs instead of their homes during times of civil conflict in Rio de Janeiro neighborhoods).

The Manual specified the CTI-TS components that should remain the same across a broad range of contexts; and standardized the training process for them. In addition, it specified the CTI-TS components that could be adapted according to the particular sociocultural context and service system in which the CTI-TS is being used.

The didactic phase comprised 54 hours of training sessions, which covered concepts as well as practices, but with a greater emphasis on developing practical skills for CTI-TS. This was followed by on-the-job training, with intensive supervision, in which each PSW/CMHW pair conducted the full nine-month CTI-TS intervention with one (Santiago) or two (Rio de Janeiro) patients who were eligible for but not included in the RCT.

Ongoing regular supervision of PSWs and CMHWs was a rrequirement of CTI-TS. In the RCT, supervisors were psychiatrists or psychologists, and all were trained in CTI-TS by those who originally developed it. This occurred throughout week-long meetings in New York (USA), Santiago, and Rio de Janeiro over a period of several years.

\section{- Participants: CTI-TS intervention}

For purposes of an overview, the intervention can be considered in terms of two broad objectives. One is to help the individual to develop durable connections to support systems, including both formal and informal supports, such as mental health services, primary care clinics, family, and friends. The other is to provide practical and emotional support, helping the individual to overcome a critical period of transition during which they felt especially vulnerable.

In this trial, the work of CTI-TS focused on areas identified as crucial for strengthening the individual's continuum of services and forming enduring links with his or her community supports. As in the original CTI, the role of CTI-TS workers is specifically designed to avoid becoming the primary source of care for the individual. Also as in the original CTI, the phases of CTI-TS are Initiation, Try-Out, and Transfer of Care. Initiation involves intensive in vivo work and the elaboration of a recovery-oriented plan focused on a few selected areas (e.g., family, CMHCs, primary care). Try-out considers lessening involvement and observing how the plan made in the prior phase worked in practice. Finally, Transfer of Care is devoted primarily to ensuring the durability of what was achieved in the previous phases. The patient, CTI-TS workers, and other key formal and informal supports meet to specifically review longer-term responsibilities and goals. 


\section{Control arm}

\section{- Participants: control intervention}

Usual care corresponded to the care that was typically delivered at CMHCs in each city. Usual care was, overall, similar in both cities. For instance, CMHCs usually (i) served a population enrolled in the public health care system; (ii) provided mental health care to adults with psychoses and other severe mental disorders; and (iii) had a diverse team of professionals that included psychiatrists, psychologists, psychiatric nurses, social workers, occupational therapists, and family counselors. The CMHCs offered a wide range of services such as psycho-pharmacological treatment and psychosocial services. However, as stated before, the provision of services outside the clinic was limited in terms of building patients' connections with primary care and community resources 12,14. Providers at primary care, who had some training on mental health, were responsible for identifying people with psychosis and referring them to their respective CMHC, in each city. CMHCs could also refer patients to their primary care centers for more general health and social services but, as noted above, this was not done sufficiently 13,17 .

\section{Fidelity assessment}

Intervention fidelity was assessed by applying the CTI fidelity scale 27 , which consists of 20 items that evaluate the degree to which providers implemented the key elements of the CTI model (e.g., shared decision-making). Item-level ratings can be combined to compute an overall fidelity score (CTI-TS Training Manual). The fidelity score uses a 5-point Likert scale (from $1=$ not implemented at all, to 5 = ideally implemented).

\section{Outcomes}

A description of assessments included in this trial is provided below (Table 1). When measures had not been translated and adapted to each context, we translated these from English to Spanish/Portuguese and vice versa, following the WHO's guidelines 28 . Assessments were conducted by blinded and external interviewers, who had sufficient experience in conducting clinical evaluations.

\section{- Primary outcomes}

Primary outcomes are health-related quality of life and unmet needs at 18 months. Further analyses consider changes over time across the three time points - namely: baseline, 9 months, and 18 months - for these two outcomes, as noted below.

\section{Table 1}

List of assessments included in the randomized controlled trial (RCT) of Critical Time Intervention-Task Shifting (CTI-TS).

\begin{tabular}{lcc}
\hline Outcome & Assessment & Timing \\
\hline $\begin{array}{l}\text { Quality of life } \\
\text { Unmet needs }\end{array}$ & WHO Quality of Life Scale - Brief Version & Camberwell Assessment of Need \\
Level of disability & WHO Disability Assessment Schedule & Baseline, 9 months, 18 months \\
Recovery orientation & Recovery Assessment Scale & Baseline, 9 months, 18 months \\
Continuity of care & CONNECT: A Measure of Continuity of Care & Baseline, 9 months, 18 months \\
Course of illness & Life Chart Schedule & Baseline, 9 months, 18 months \\
Public stigma & Perceived Devaluation and Discrimination Scale & Baseline, 9 months, 18 months \\
Internalized stigma & Internalized Stigma of Mental Illness & Baseline, 9 months, 18 months \\
Alcohol, smoking, substance use & WHO Alcohol, Smoking and Substance Involvement Screening Test Schedule & Baseline, 9 months, 18 months \\
\end{tabular}


Health-related quality of life was assessed by the WHO Quality of Life - Brief Version (WHOQOLBREF) 29. This instrument has 26 items and measures the following domains: physical health, psychological health, social relationships, and environment, with two additional general questions. The Camberwell Assessment of Needs (CAN) ${ }^{30}$ was used to measure unmet needs. This instrument evaluates 22 areas of need such as accommodation, food, safety to self, among others.

\section{- Secondary outcomes}

Six secondary outcomes are included in this study: level of disability (World Health Organization Disability Assessment Schedule - WHODAS 2.0) 31; orientation toward self-directed recovery (Recovery Assessment Scale - RAS) 32; continuity of care and course of illness (CONNECT and the Life Chart Schedule) 33,34; perceived stigma (Perceived Devaluation and Discrimination Scale - PDD) 35; self-stigma (Internalized Stigma of Mental Illness - ISMI) 36; and substance use (WHO Alcohol, Smoking and Substance Involvement Screening Test Schedule - WHO ASSIST) 37.

\section{Sample size (based on precision of confidence intervals)}

Sample size was calculated based on the precision (or margin of error) of our estimators. There are three main reasons why we chose to calculate sample size based on precision rather than conventional statistical power. First, such estimation is well known in the literature ${ }^{38}$. Second, this method is preferred for pilot trials because our sample size is too small for us to conduct a full-powered study. Third, the purposes of this pilot RCT included the estimation of key mission-critical parameters for designing a subsequent regional, phase III RCT. Those parameters include subject accrual rates, retention and attrition rates, prevalence of discrete outcomes, means of continuous outcomes, standard deviations of outcome measures and, in the case of longitudinal data, intra-class correlations measuring within-subject correlations over time. While the sample size in the pilot study might be too small to estimate the intervention effect adequately, large sample sizes are not required to sufficiently estimate these mission-critical parameters for planning a future RCT, with an appropriate sample size, based on conventional computation of statistical power analysis.

We describe here how precision was calculated for the WHOQOL-BREF. This formula uses the standard deviation $(\mathrm{SD}=15)$ for WHOQOL-BREF, as previously reported in the literature, and an intra-class correlation coefficient of 0.01 .

If we consider that 30 subjects in the Santiago treatment group are correlated $\Rightarrow$ Number of independent observations in the Santiago treatment group $=\frac{30}{1+(30-1)(0.01)}=23$.

Similarly, 25 subjects in the Rio de Janeiro treatment group are correlated $\Rightarrow$ Number of independent observations in the Rio treatment group $=\frac{25}{1+(25-1)(0.01)}=20$.

Total number of independent observations per arm $=43$.

Width of confidence interval $=1.96(15) \sqrt{\frac{1}{43}+\frac{1}{43}}=6.3$.

\section{Data management and analysis}

\section{- Data management}

A tracking system was implemented in each city for recording contacts with participants and caregivers, as well as for bringing to light the screening process and follow-up procedures. Data from each assessment were recorded on paper forms, and then recorded via web-based data entry screens into a secure database, built and maintained by the CU DCC. For all instruments, data entry screens were available in English, Spanish, and Portuguese. Regardless of site and language of entry, data were transmitted securely via the Internet and stored in a SIR/XS relational database (http://www.sir.com. $\mathrm{au} /$ ) maintained by the CU DCC. 


\section{- Plan for data analysis}

We will conduct descriptive analyses, including frequency distributions and measures of central tendency and dispersion, with 95\% confidence intervals. Bivariate analyses will be based on chi-square, Fisher's exact, Student's t-test or rank-sum tests, as appropriate. Then, we shall perform multiple imputation for missing data, using 20 imputations and a fully conditional model based on Markov Chain Monte Carlo.

Our main analyses of outcomes will be conducted using multiple imputation, as described above, and the intention-to-treat sample (i.e. based on the group the participant was allocated in). Primary outcomes at 18 months will be analyzed by Generalized Estimating Equations (GEE), with observations clustered within sites. For longitudinal analyses, to examine trends over time in primary outcomes (with measures from baseline, 9-month follow-up, and 18-month follow-up), we will use threelevel multilevel models, with observations at different times clustered within observations, which are in turn clustered within sites. Similar procedures will be used for analyzing secondary outcomes.

\section{Ethical considerations}

This study protocol was approved by the Institutional Review Board (IRB) at Columbia University, the local IRB at University of Chile, the local IRB at UFRJ, and the Brazilian National Ethical Committee. Additionally, the NIMH Global Mental Health DSMB monitored the study. The DSMB role was to ensure that researches and intervention team members in Rio and Santiago understood the processes in place to protect the safety of study participants, and to verify whether the study protocol and procedures were being followed correctly.

\section{Discussion}

We have described the study protocol of a pilot RCT of CTI-TS and some of the lessons we learned while implementing it. To our knowledge, this was the first RCT of a recovery-oriented intervention for people with psychoses conducted in Latin America, and elsewhere in any LMIC. As noted previously, the CTI-TS was designed to address gaps in the offering of mental health care for people with psychoses by providing in vivo community services, promoting continuity of care between health service providers, employing peers and community workers, and promoting recovery-oriented services that encourage empowerment and a positive sense of self among people with psychoses, despite them having certain mental and physical deficits. Although major mental health reforms have taken place over the last years in countries such as Brazil and Chile, recovery-oriented interventions are not generally offered and have not been tested in these countries.

We note the potential value of using non-professionals such as CMHWs and PSWs in the provision of CTI and, more generally, mental health services. They can provide some of the services delivered by professionals (i.e. medication monitoring) but also support and promote recovery orientation among people with psychosis. PSWs, in particular, have the unique experience of developing strategies to overcome their own mental health difficulties. Therefore, they can provide role modelling in a way that only a person with lived-experience can do. For a vulnerable group such as individuals with serious mental disabilities, the employment of such workers has the potential to facilitate the process of bringing people into social and health services, as well as connecting them with community resources and family members. We hope this trial contributes to legitimize and institutionalize their role in mental health services in Latin America, similarly to what occurred in the U.S. and some other HICs, where peer services are frequently offered for people with psychoses as part of regular care 39.

Finally, our experience suggests that regionally generated research evidence can be key for the dissemination and widespread adoption of effective mental health reforms. Evidence from HICs on interventions for people with psychotic disorders often cannot be universally implemented in Latin American countries. Some of these interventions are costly and complex, and/or ill-suited to the service systems and sociocultural contexts of the marginalized communities where so many people live. A regional evidence base would surely be more applicable and likely more persuasive to 
those who promote and implement mental health policies. As noted above, the RCT of CTI-TS was specifically tailored to help facing this challenge. Our hope is that this trial provides a foundation for planning a large-scale multi-site RCT, to establish the efficacy of recovery-oriented intervention such as CTI-TS in Latin America.

\section{Contributors}

F. Mascayano, K. Fader, and E. Susser designed and wrote the first draft of the manuscript. R. Alvarado, H. F. Andrews, J. N. Baumgartner, M. S. Burrone, S. Conover, J. Cintra, C. M. Dahl, S. Galea, P. Gorroochurn, M. J. Jorquera, G. M. Lovisi, F. M. Souza, C. Pratt, G. Rojas, M. E. Restrepo-Toro, R. Rosenheck, K. R. Sarução, S. Schilling, P. Stastny, E. Tapia, M. T. Cavalcanti, E. Valencia, and L. H. Yang provided valuable feedback on methods, procedures, intervention description, and ethical considerations.

\section{Additional informations}

ORCID: Franco Mascayano (0000-0002-3118504X); Ruben Alvarado (0000-0002-8091-0324); Howard F. Andrews (0000-0002-7726-0551); Maria Jose Jorquera (0000-0003-0115-7774); Giovanni Marcos Lovisi (0000-0003-0521-0202); Flavia Mitkiewicz de Souza (0000-0002-5965-6026); Charissa Pratt (0000-0002-0924-9721); Graciela Rojas (0000-0002-9577-7415); Maria E. Restrepo-Toro (0000-0003-1733-6240); Kim Fader (0000-00018323-9479); Prakash Gorroochurn (0000-00031613-7223); Sandro Galea (0000-0002-7534-0945); Catarina Magalhães Dahl (0000-0001-7058-9875); Jacqueline Cintra (0000-0003-2951-979X); Sarah Conover (0000-0002-9647-7780); Maria Soledad Burrone (0000-0002-9641-8350); Joy Noel Baumgartner (0000-0002-1783-8972); Robert Rosenheck (0000-0003-4314-4592); Sara Schilling (0000-0001-7082-7650); Keli Rodrigues Sarução (0000-0001-9175-0824); Peter Stastny (0000-00025028-8642); Eric Tapia (0000-0001-8138-1797); Maria Tavares Cavalcanti (0000-0003-1872-4210); Eliecer Valencia (0000-0001-7878-5141); Lawrence H. Yang (0000-0001-7779-7423); Ezra Susser (0000-0001-7665-4826).

\section{Acknowledgments}

Research in this publication was supported by the United States National Institute of Mental Health under award U19MH095718. Content is the sole responsibility of the authors and does not necessarily represent the official views of the United States National Institute of Health.

\section{References}

1. Levav I, González Uzcátegui R. The roots of the Caracas Declaration. In: Rodriguez J, editor. Mental health care reform: 15 years after Caracas. Washington DC: Pan American Health Organization; 2007. p. 44-50.

2. Ministerio de Salud del Perú. Regional Conference on Community Mental Health, Lima, 2016. http://www.paho.org/per/index. php?option $=$ com_content $\&$ view $=$ article $\&$ id =3187:2016-01-05-21-23-09\&Itemid $=900$ (accessed on 17/Aug/2017).

3. Organización Panamericana de la Salud. WHOAIMS: Informe sobre los sistemas de salud mental en América Latina y el Caribe. http:// www.paho.org/per/images/stories/FtPage/ 2013/WHO-AIMS.pdf (accessed on 17/Aug/ 2017).

4. Minoletti A, Sepúlveda R, Horvitz-Lennon M. Twenty years of mental health policies in Chile: lessons and challenges. Int J Ment Health 2012; 41:21-37.

5. Loch AA, Gattaz WF, Rössler W. Mental healthcare in South America with a focus on Brazil: past, present, and future. Curr Opin Psychiatr 2016; 29:264-9.

6. Minoletti A, Galea S, Susser E. Community mental health services in Latin America for people with severe mental disorders. Public Health Rev 2012; 34:13.

7. Caldas de Almeida JM, Horvitz-Lennon M. Mental health care reforms in Latin America: an overview of mental health care reforms in Latin America and the Caribbean. Psychiatr Serv 2010; 61:218-21.

8. Caldas de Almeida JM. Mental health services development in Latin America and the Caribbean: achievements, barriers and facilitating factors. Int Health 2013; 5:15-8.

9. Stastny P. Introducing peer support work in Latin American mental health services. Cad Saúde Colet (Rio J.) 2012; 20:473-81.

10. Le Boutillier C, Leamy M, Bird VJ, Davidson L, Williams J, Slade M. What does recovery mean in practice? A qualitative analysis of international recovery-oriented practice guidance. Psychiatr Serv 2011; 62:1470-6.

11. Davidson L, O'Connell MJ, Tondora J, Lawless M, Evans AC. Recovery in serious mental illness: a new wine or just a new bottle? Prof Psychol Res Pr 2005; 36:480-7. 
12. Markkula N, Alvarado R, Minoletti A. Adherence to guidelines and treatment compliance in the Chilean national program for firstepisode schizophrenia. Psychiatr Serv 2011; 62:1463-9.

13. Costa PH, Colugnati FA, Ronzani TM. Mental health services assessment in Brazil: systematic literature review. Ciênc Saúde Colet 2015; 20:3243-53.

14. Nascimento AD, Galvanese AT. Evaluation of psychosocial healthcare services in the city of Sao Paulo, Southeastern Brazil. Rev Saúde Pública 2009; 43:8-15.

15. World Health Organization. Comprehensive mental health action plan 2013-2020. Geneva: World Health Organization; 2013.

16. Mateus MD, Mari JJ, Delgado PG, AlmeidaFilho N, Barrett T, Gerolin J, et al. The mental health system in Brazil: policies and future challenges. Int J Ment Health Syst 2008; 2:12.

17. Alvarado R, Minoletti A, González FT, Küstner BM, Madariaga C, Sepúlveda R. Development of community care for people with schizophrenia in Chile. Int J Ment Health 2012; 41:48-61.

18. Susser E, Valencia E, Conover S, Felix A, Tsai WY, Wyatt RJ. Preventing recurrent homelessness among mentally ill men: a "critical time" intervention after discharge from a shelter. Am J Public Health 1997; 87:256-62.

19. Herman D, Conover S, Felix A, Nakagawa A, Mills D. Critical time intervention: an empirically supported model for preventing homelessness in high risk groups. J Prim Prev 2007; 28:295-312.

20. Herman D, Conover S, Gorroochurn P, Hinterland K, Hoepner L, Susser E. A randomized trial of critical time intervention in persons with severe mental illness following institutional discharge. Psychiatr Serv 2011; 62: 713-9.

21. de Souza FM, Valencia E, Dahl C, Cavalcanti MT. A violência urbana e suas consequências em um centro de atenção psicossocial na zona norte do município do Rio de Janeiro. Saúde Soc $2011 ; 20: 363-76$

22. Silva TFC, Abelha L, Lovisi GM, Calavacanti MT, Valencia ES. Quality of life assessment of patients with schizophrenic spectrum disorders from Psychosocial Care Centers. J Bras Psiquiatr 2011; 60:91-8.

23. Calvacanti MT, Carvalho MA, Valencia E, Dahl CM, Souza FM. Adaptação da "Critical Time Intervention" para o contexto brasileiro e sua implementação junto a usuários dos Centros de Atenção Psicossocial do município do Rio de Janeiro. Ciênc Saúde Colet 2011; 16:463542.

24. Lovisi G, Mari J, Valencia E, editors. The psychological impact of living under violence and poverty in Brazil. New York: Nova Science Publishers; 2010.

25. Ribeiro JM, Inglez-Dias A. Políticas e inovação em atenção à saúde mental: limites ao descolamento do desempenho do SUS. Ciênc Saúde Colet 2011; 16:4623-34.
26. Appelbaum PS, Grisso T. MacArthur competence assessment tool for clinical research (MacCAT-CR). Sarasota: Professional Resource Press/Professional Resource Exchange; 2001.

27. da Silva TF, Lovisi GM, Conover S. Developing an instrument for assessing fidelity to the intervention in the Critical Time InterventionTask Shifting (CTI-TS): preliminary report. Archives of Psychiatry and Psychotherapy 2014; 16:55-62.

28. World Health Organization. Process of translation and adaptation of instruments guidelines. http://www.who.int/substance_abuse/re search_tools/translation/en/ (accessed on 17/ Aug/2017).

29. The WHOQOL Group. Development of the World Health Organization WHOQOL-BREF Quality of Life Assessment. Psychol Med 1998; 28:551-8.

30. Phelan M, Slade M, Thornicroft G, Dunn G, Holloway F, Wykes T, et al. The Camberwell Assessment of Need: the validity and reliability of an instrument to assess the needs of people with severe mental illness. Br J Psychiatry 1995; 167:589-95.

31. Üstün TB, Chatterji S, Kostanjsek N, Rehm J, Kennedy C, Epping-Jordan J, et al. Developing the World Health Organization Disability Assessment Schedule 2.0. Bull World Health Organ 2010; 88:815-23.

32. Corrigan PW, Salzer M, Ralph RO, Sangster Y, Keck L. Examining the factor structure of the recovery assessment scale. Schizophr Bull 2004; 30:1035-41.

33. Ware NC, Dickey B, Tugenberg T, McHorney CA. CONNECT: a measure of continuity of care in mental health services. Ment Health Serv Res 2003; 5:209-21.

34. Susser E, Finnerty M, Mojtabai R, Yale S, Conover S, Goetz R, et al. Reliability of the life chart schedule for assessment of the long-term course of schizophrenia. Schizophr Res 2000; 42:67-77.

35. Link BG, Cullen FT, Struening E, Shrout PE, Dohrenwend BP. A modified labeling theory approach to mental disorders: an empirical assessment. Am Sociol Rev 1989; 54:400-23.

36. Ritsher JB, Otilingam PG, Grajales M. Internalized stigma of mental illness: psychometric properties of a new measure. Psychiatr Res 2003; 121:31-49.

37. WHO ASSIST Working Group. The Alcohol, Smoking and Substance Involvement Screening Test (ASSIST): development, reliability and feasibility. Addiction 2002; 97:1183-94.

38. Friedman LM, Furberg C, DeMets DL, Reboussin DM, Granger CB. Fundamentals of clinical trials. 5th Ed. New York: Springer; 2015.

39. Chinman M, George P, Dougherty RH, Daniels AS, Ghose SS, Swift A, et al. Peer support services for individuals with serious mental illnesses: assessing the evidence. Psychiatr Serv 2014; 65:429-41. 


\section{Resumo}

Diversos países latino-americanos já alcançaram avanços notáveis na oferta de assistência em saúde mental para pessoas com psicoses. No entanto, as clinicas de saúde mental geralmente realizam atividades de extensão muito limitadas dentro das comunidades, tendem a ter vínculos fracos com a assistência primária, raramente envolvem os próprios pacientes nos cuidados e poucas vezes prestam serviços orientados para a recuperação. $O$ artigo descreve um estudo piloto randomizado e controlado sobre a Critical Time Intervention-Task Shifting (CTI-TS), que teve como objetivo analisar essas limitações. O estudo piloto foi realizado em Santiago (Chile) e no Rio de Janeiro (Brasil). Teve como meta a inclusão de 110 pessoas com psicose, recrutadas no momento da entrada em clinicas comunitárias de saúde mental. Os participantes foram randomizados para o CTI-TS ou para os cuidados usuais. Aqueles alocados ao grupo da intervenção receberam os cuidados usuais e os serviços de CTI-TS ao longo de 9 meses. Os desfechos primários incluíram a qualidade de vida (WHO Quality of Life Scale - Brief Version) $e$ as necessidades não atendidas (Camberwell Assessment of Needs) no acompanhamento aos 18 meses. Os desfechos primários aos 18 meses serão analisados com a técnica de Equações de Estimação Generalizadas (GEE), com as observações agrupadas dentro dos locais do estudo. Serão utilizados modelos em três níveis para examinar as tendências temporais nos desfechos primários. Procedimentos semelhantes serão utilizados para analisar os resultados secundários. Espera-se que o estudo forneça uma base para planejar um estudo randomizado e controlado em grande escala e em múltiplos locais para estabelecer a eficácia da intervenção orientada para a recuperação, a exemplo da CTI-TS, na América Latina.

Serviços Comunitários de Saúde Mental; Transtornos Psicóticos; Ensaio Clínico Controlado Aleatório; Saúde Global

\section{Resumen}

Varios países latinoamericanos han realizado notables progresos para ofrecer servicios comunitarios de salud mental a personas con psicosis. Sin embargo, las clínicas de salud mental generalmente tienen un alcance muy limitado en la población; además de una escasa relación con a la atención primaria; raramente involucran a los pacientes en la prestación de asistencia; y habitualmente no proporcionan servicios orientados a la recuperación. Este trabajo describe una prueba piloto controlada aleatorizada (RCT por sus siglas en inglés) de Critical Time Intervention-Task Shifting (CTI-TS por sus siglas en inglés) (con número de registro: NCT01995864), cuyo objetivo estaba dirigido a las limitaciones mencionadas anteriormente. La prueba piloto RCT se realizó en Santiago (Chile) y en Río de Janeiro (Brasil). Seleccionamos la inclusión de 110 personas con psicosis, que fueron incorporadas al estudio en el momento de su entrada a las clínicas de salud mental comunitarias. En la prueba se asignaron aleatoriamente a los participantes la intervención CTI-TS o la asistencia médica común. Quienes estuvieron asignados al grupo de intervención recibieron asistencia médica común, además, de los servicios propios del CTI-TS durante un período de 9 meses. Los resultados primarios incluyen un seguimiento de calidad de vida (WHO Quality of Life Scale - Brief Version) y de necesidades insatisfechas (Camberwell Assessment of Needs) durante 18 meses. Los resultados primarios a los 18 meses se analizarán usando Ecuaciones de Estimación Generalizadas (GEE por sus siglas en inglés) con observaciones agrupadas en los propios lugares. Usaremos modelos multinivel de tres niveles para examinar las tendencias temporales en los resultados primarios. Se usarán procedimientos similares para analizar los resultados secundarios. Nuestra esperanza es que esta prueba proporcione una base para la planificación de una prueba controlada aleatorizada a gran escala en múltiples lugares, con el fin de establecer la eficacia de las intervenciones orientadas a la recuperación como las CTI-TS en Latinoamérica.

Servicios Comunitarios de Salud Mental; Trastornos Psicóticos; Ensayo Clínico Controlado Aleatorio; Salud Global
Submitted on 01/Jun/2018

Final version resubmnitted on 20/Feb/2019

Approved on 08/Mar/2019 